\begin{tabular}{|c|l|}
\hline Title & Reciprocal phenoty pic plasticity in a predator-prey interaction between larval amphibians \\
\hline Author(s) & Kishida, Osamu; Mizuta, Yuuki; Nishimura, Kinya \\
\hline Citation & $\begin{array}{l}\text { Ecology, 87(6), 1599-1604 } \\
\text { https://loi.org/10.1890/0012-9658(2006)87[1599:RPPIAP]2.0.c0;2 }\end{array}$ \\
\hline Issue Date & 2006-06 \\
\hline Doc URL & http://hdl.handle.net/2115/30191 \\
\hline Type & article \\
\hline File Information & ECOL87-6.pdf \\
\hline
\end{tabular}

Instructions for use 


\title{
RECIPROCAL PHENOTYPIC PLASTICITY IN A PREDATOR-PREY INTERACTION BETWEEN LARVAL AMPHIBIANS
}

\author{
Osamu Kishida, ${ }^{1}$ Yuuki Mizuta, and Kinya Nishimura \\ Graduate School of Fisheries Sciences, Hokkaido University, Hakodate 041-8611, Hokkaido, Japan
}

\begin{abstract}
In biological interactions, phenotypic change in interacting organisms induced by their interaction partners causes a substantial shift in some environmental factor of the partners, which may subsequently change their phenotype in response to that modified environmental factor. Few examples of such arms-race-like plastic responses, known as reciprocal phenotypic plasticity, have been identified in predator-prey interactions. We experimentally identified a reciprocal defensive plastic response of a prey species against a predator with a predaceous phenotype using a model system of close predator-prey interaction. Rana pirica tadpoles (the prey species) were reared with larvae of the salamander Hynobius retardatus (the predator species) having either a predaceous or a typical, nonpredaceous phenotype. The $H$. retardatus larvae with the predaceous phenotype, which is known to be induced by the presence of $R$. pirica tadpoles, induced a more defensive phenotype in the tadpoles than did larvae with the typical phenotype. The result suggests that the reciprocal phenotypic plasticity of $R$. pirica tadpoles is in response to a phenotype-specific signal under a close-signal recognition process.
\end{abstract}

Key words: arms race; bulgy phenotype; coevolution; Hynobius retardatus; inducible defense; inducible offense; predator-induced plasticity; Rana pirica.

\section{INTRODUCTION}

Organisms are exposed to various biotic and abiotic environmental selective agents that are spatially and temporally variable. Phenotypic plasticity, the environmentally sensitive production of alternative phenotypes by given genotypes (defined by Stearns 1989), is a powerful means of adaptation to changing environments that is both prevalent among many taxa and occurs in various traits (Tollrian and Harvell 1999, Pigliucci 2001, DeWitt and Scheiner 2004). As the number of investigations of phenotypic plasticity by evolutionary biologists and ecologists increases, there is a growing recognition of the importance of phenotypic plasticity at the organismal level (Schlichting and Pigliucci 1998, DeWitt and Scheiner 2004) and, because of its ecological consequences, at the level of community assemblages (Trussell et al. 2002, Werner and Peacor 2003, Miner et al. 2005).

Biological interactions such as mutualism, competition, or predation are temporally and spatially variable ecological processes, and it is commonly observed that

Manuscript received 13 October 2005; revised 14 December 2005; accepted 20 December 2005. Corresponding Editor: J. Loman.

${ }^{1}$ E-mail: kishida@fish.hokudai.ac.jp the interacting individuals plastically respond to the environmental regimes created by their interaction partners. Numerous studies have reported phenotypic plasticity in species interactions and have identified the adaptive functions of the induced phenotypes (Tollrian and Harvell 1999, Pigliucci 2001, DeWitt and Scheiner 2004). The induction of adaptive phenotypes in interacting organisms implies that the phenotypic change induced in one of the interacting partners by the other results in a substantial shift of some environmental factor for the inducing partner (Agrawal 2001). The modified environmental factor caused by the phenotypic change may lead the partner to respond with a phenotypic change of its own. That is, a reciprocal phenotypic plasticity, termed by Kopp and Tollrian (2003), can be expected to be induced by the opposing environmental shift in the biological interaction. For example, in a mutualistic interaction, an organism may increase its rewards in response to increased services from its mutualistic partner. On the other hand, in an antagonistic interaction, an organism may take countermeasures against the strengthened antagonistic phenotype of its counterpart. Agrawal (2001) suggested that reciprocal phenotypic plasticity may be a result of the long-term evolution of a variable biological interaction and that it 

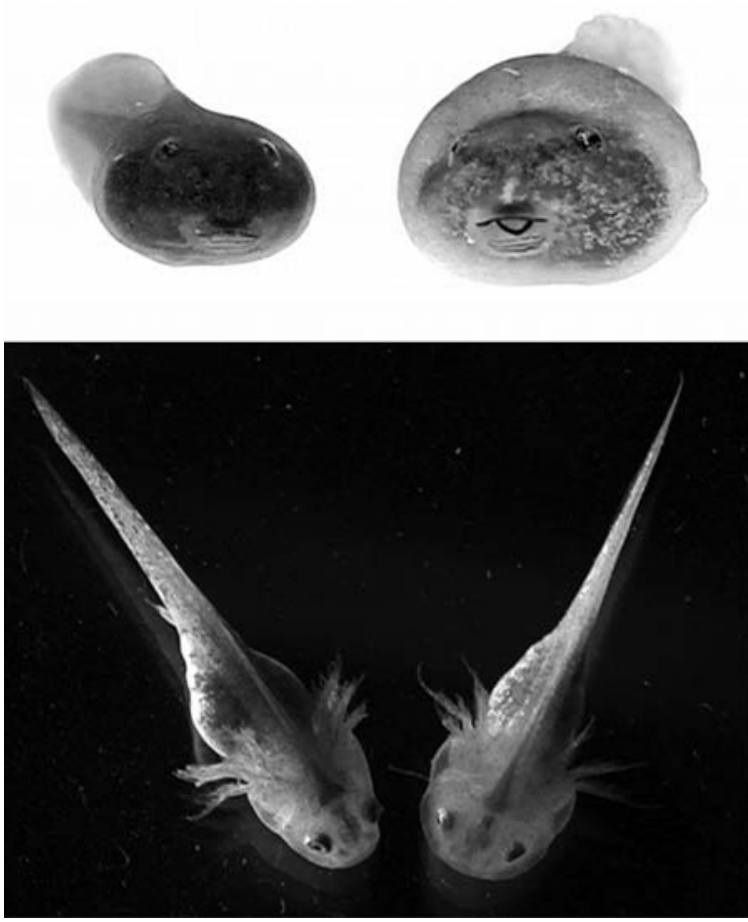

FIGURE 1. Phenotypes of larvae of the two amphibian species: Rana pirica tadpoles with the typical phenotype (upper left) and with the bulgy phenotype (upper right), and Hynobius retardatus with the typical phenotype (lower left) and with the predaceous phenotype (lower right).

may be common in biological interactions and a primary determinant of an organism's phenotype in nature.

A predator-prey system is a major antagonistic interaction system that sometimes occurs stochastically at both micro- and mesoscales. Morphological plasticity is pervasive in predator-prey interactions; that is, numerous prey species are induced by predators to exhibit defensive morphological phenotypes (inducible defense; reviewed by Tollrian and Harvell 1999), and several predator species develop predatory morphological phenotypes in the presence of certain prey species (inducible offense; e.g., Smith and Palmer 1994, Frankino and Pfennig 2001, Aubret et al. 2004). Because both kinds of phenotypic plasticity alter predator-prey interactions, arms-race-like reciprocal phenotypic plasticity can be expected to be common in predator-prey interactions (Agrawal 2001). There are very few studies on reciprocal phenotypic plasticity in predator-prey systems. The known examples are limited taxonomically to Protozoa (Wicklow 1988, Kopp and Tollrian 2003).

Empirical evidence of a relevant trait would enable us to consider its mechanism from both ecological and evolutionary perspectives, and thus would lead to an understanding of phenotypic diversity in nature and offer deeper insight into the evolution and ecological consequences of the phenotypic design. In the present study, we sought to identify experimentally a reciprocal plastic defensive response in a prey species against a predator with an offensive phenotype in a model system of an intimate predator-prey interaction.

Amphibian larvae are an excellent model system for studying phenotypic plasticity in biological interactions (Van Buskirk and Relyea 1998, Relyea 2002a, b, Benard 2004). Larvae of many amphibian species can be induced to exhibit morphological defenses (Kishida and Nishimura 2004, Teplitsky et al. 2005, Wilson et al. 2005) when threatened by various predators, and larvae of several species exhibit predaceous morphological changes when the density of conspecifics (Hoffman and Pfennig 1999, Michimae and Wakahara 2001) or of certain prey species (Frankino and Pfennig 2001, Michimae and Wakahara 2002) is high in their environment.

Predator-prey interactions between Hynobius retardatus larvae and Rana pirica tadpoles are an ideal model system for identifying reciprocal phenotypic plasticity because the predator-prey relationships in their natural pond habitats are temporally and spatially variable and the larvae of both amphibian species reciprocally exhibit antagonistic morphological changes in each other's presence (Fig. 1). R. pirica tadpoles are induced to develop bulgy bodies when they are in close proximity to larval $H$. retardatus, which is a swallowing-type predator (Kishida and Nishimura 2004; see Plate 1). This is true, regardless of the phenotype of the $H$. retardatus larvae (O. Kishida, unpublished data). Conversely, when the density of $R$. pirica tadpoles is high, $H$. retardatus larvae are induced to develop a highly predaceous morphology, called the predaceous phenotype, which is characterized by a large gape size and effectively allows them to swallow large prey (Michimae and Wakahara 2002). These two phenotypic plasticities have antagonistic functions, because predation success depends greatly on the balance between the gape size of the $H$. retardatus larvae and the body size of $R$. pirica tadpoles (Ohdachi 1994, Kishida and Nishimura 2004).

$R$. pirica tadpoles in ponds in which $H$. retardatus larvae with the predaceous phenotype dominate are subject to an intensified predation risk compared with those in ponds in which $H$. retardatus with the typical, nonpredaceous phenotype dominate. Natural selection might favor $R$. pirica tadpoles that can develop a bulgier phenotype in the presence of $H$. retardatus larvae with the predaceous phenotype. We performed an experiment designed to determine whether predaceous $H$. retardatus larvae are more likely than typical larvae to induce the bulgier body in $R$. pirica tadpoles.

\section{Materials And Methods}

Eggs of $R$. pirica and $H$. retardatus were collected from ponds in Hokkaido, Japan, and each species was 


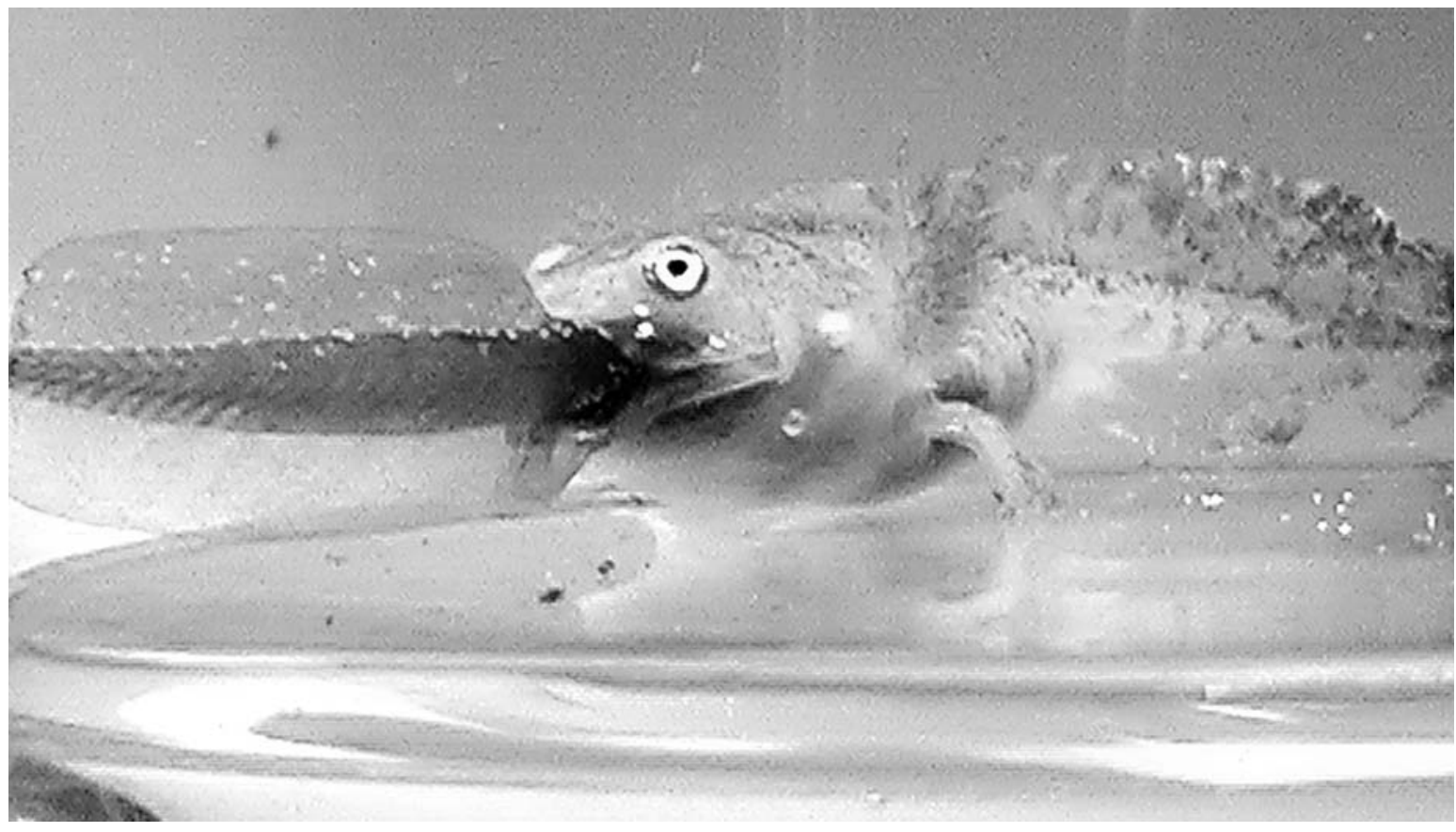

Plate 1. Gape-limited predatory salamander larva (Hynobius retardatus) consuming a Rana pirica tadpole. Photo credit: O. Kishida.

placed separately in 12-L stock aquaria. Hatchlings of R. pirica were fed rabbit chow ad libitum.

Predaceous and typical $H$. retardatus larvae were obtained by rearing the hatchlings on two different types of food. To induce the predaceous phenotype, the hatchlings were individually reared in $4.5-\mathrm{L}$ aquaria filled with 2-L of aged tap water, in which many small $R$. pirica tadpoles were daily placed as inducing prey agents. To obtain typical $H$. retardatus larvae, the hatchlings were reared individually in 0.35 - L plastic cups and fed chironomid larvae ad libitum mornings and evenings. After three weeks, we selected eight similarsized larvae from each of the two types (snout-vent lengths of the predaceous and typical $H$. retardatus larvae were $18.86 \pm 0.28 \mathrm{~mm}$ and $19.15 \pm 0.34 \mathrm{~mm}$, respectively, mean $\pm \mathrm{SD}, n=8$ ), using the phenotypic criteria of Michimae and Wakahara (2001): ratio of the head width at the level of the eyes to the largest head width. We defined larvae with a ratio $>0.86$ as having the predaceous phenotype and those with a ratio $<0.78$ as having the typical phenotype, and we adopted as the inducing agents individuals that were representative of the two phenotypes, as shown in Fig. 1. To make the morphometric measurements, each individual was placed in a small glass chamber and a photograph in ventral view was taken. Then the photographic image was projected onto a computer monitor and digitized. Preliminary experiments had shown that typical $H$. retardatus larvae of the size given previously are able to induce the bulgy phenotype in $R$. pirica tadpoles ( $\mathrm{O}$. Kishida, unpublished data). The selected $H$. retardatus larvae of each phenotype were starved for three days before the experiment.

For the experiment, $R$. pirica tadpoles were reared with either predaceous or typical H. retardatus larvae for a week to determine whether induction of the bulgy morph in the tadpoles depended on the phenotype of the $H$. retardatus larvae. Induction of the bulgy morph in $R$. pirica tadpoles requires that they be in close proximity to $H$. retardatus larvae (Kishida and Nishimura 2004), suggesting that $R$. pirica tadpoles recognize the phenotypes of the $H$. retardatus larvae by a signal that can be detected only when they are close together. Therefore, in the following experiment, we focused on the close-signal recognition process. The experiment was conducted in eight 12-L plastic aquaria $(36.5 \times 25.0 \mathrm{~cm}$ in surface area and $13.5 \mathrm{~cm}$ in height), each filled with $5 \mathrm{~L}$ of aged tap water. Each aquarium was divided by a mesh partition (mesh size of $1 \mathrm{~mm}$ ) into two, equal-sized arenas, each of which was an experimental unit. We randomly assigned 60 similarly sized, 10 -d-old $R$. pirica tadpoles (snoutvent length $=7.94 \pm 0.88 \mathrm{~mm}$, mean $\pm \mathrm{SD}, n=20$ ) to each arena of each aquarium. Because there are large variations in sizes of larvae of the two amphibian species in natural pond habitats, the size relationship between the focal $R$. pirica tadpoles and the inducing agents used in the experiment is appropriate. One $H$. retardatus larva with the predaceous phenotype was placed in one arena 


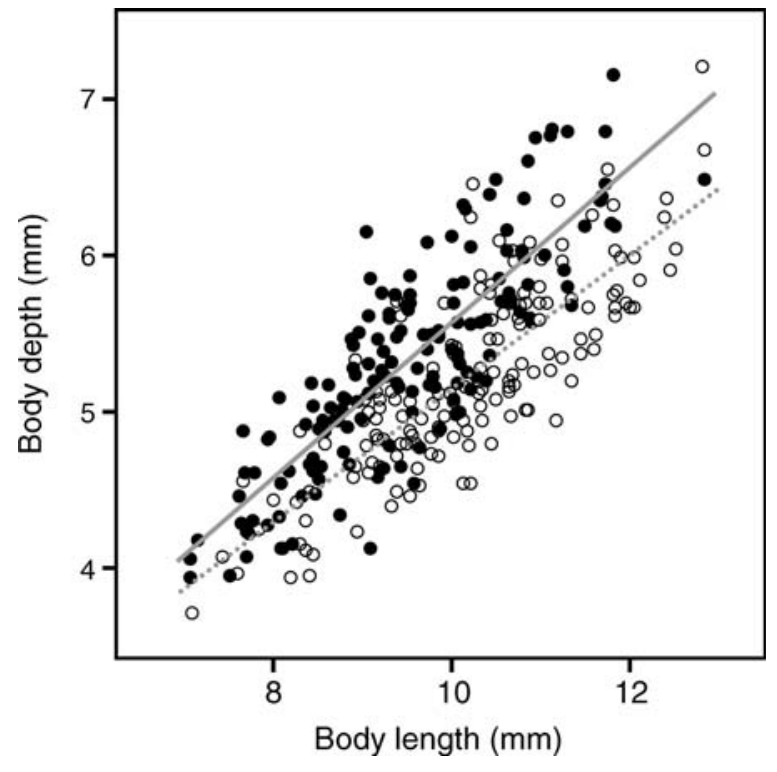

FIG. 2. The relationship between body depth and body length of the $R$. pirica tadpoles in the two treatments (typical treatment, open circles; predaceous treatment, solid circles) as an indicator of the extent of induction of the bulgy phenotype. Each point represents an individual tadpole. The regression lines of body depth $(y)$ on body length $(x)$ show typical treatment, dotted line $\left(y=0.875+0.426 x, r^{2}=0.67\right)$; and predaceous treatment, solid line $\left(y=0.551+0.500 x, r^{2}=0.70\right)$.

(predaceous treatment) of each aquarium, and one $H$. retardatus larva with the typical phenotype was placed in the other arena (typical treatment) of the same aquarium. The two $H$. retardatus larvae in the same aquarium were chosen to be of similar length, the difference in snout-vent length between the two phenotypes was no more than $0.5 \mathrm{~mm}$. Therefore, although the $R$. pirica tadpoles subjected to the different treatments shared the same water, potentially containing chemicals produced by both salamanders (the inducing agents), they were closely exposed only to one inducing agent with either the predaceous or typical phenotype. The $H$. retardatus larvae in the arenas were free to eat the $R$. pirica tadpoles throughout the experiment. We counted the surviving $R$. pirica tadpoles every two days and determined whether the number of tadpoles differed between treatments and among aquaria. Then, in order to keep the density of tadpoles equal, we equalized the numbers of tadpoles in all arenas by random deletion until all had the same number of tadpoles as the arena with the minimum number.

$R$. pirica tadpoles were fed rabbit chow ad libitum during the experiment. Rearing water was completely changed every two days. The experiment was conducted in a laboratory at $16^{\circ} \mathrm{C}$ with a natural day : night (14:10) cycle. After one week, the experiment was terminated, and $20 \mathrm{R}$. pirica tadpoles were randomly selected from each arena for morphological measurement. The selected tadpoles were killed in $10 \%$ ethanol. They were placed in a small glass chamber, and photographs in lateral view were taken. Then the photographic images were projected onto a computer monitor, and the following two traits were digitized: maximum body depth and body length (from the tip of the snout to the tail joint).

Kishida and Nishimura (2004) previously showed that body depth is an appropriate indicator of the morphological trait of bulginess. We adopted body length as the canonical size measurement because it is stable, whereas most other measurable traits (e.g., body width, tail length, and total length) are changed by the induction of the bulgy phenotype (i.e., neither a composite variable of various morphological traits such as the first principal component in a principal components analysis nor mass is an appropriate canonical size measurement; see Kishida and Nishimura 2005). Thus, the data of body depth were corrected for variation in the size measurement. That is, separate regressions of body depth on body length were calculated from the data of each treatment. Then, the residuals were calculated from the regression results to evaluate the extent of induction of the bulgy phenotype. Arena means of the size-corrected variables were used in the statistical analysis.

\section{ReSults}

The number of preyed-upon tadpoles did not differ between the two treatments: $19.62 \pm 3.58(n=8)$ in the predaceous treatment, $20.38 \pm 2.62(n=8)$ in the typical treatment (paired $t$ test, $t_{7}=0.386, P=0.71$ ). To test our main hypothesis that induction of the bulgy morph in the tadpoles depends on the phenotype of the $H$. retardatus larvae, we used a paired $t$ test to compare the means of size-corrected body depth of the tadpoles in the two arenas of each aquarium. (The arena means of the residuals in the predaceous and typical treatments were $0.198 \pm 0.074 \mathrm{~mm}$ and $-0.198 \pm 0.079 \mathrm{~mm}$, respectively; mean $\pm \mathrm{SE}, n=8$.) This test found a significant difference between the two treatments $\left(t_{7}=\right.$ 3.579, $P=0.009$; Fig. 2).

\section{DiscusSION}

Our experimental results indicated that the predaceous $H$. retardatus larvae induced $R$. pirica tadpoles to acquire bulgier bodies than did the typical larvae (Fig. 2).

That the number of tadpoles preyed upon was the same between the two treatments is not considered to imply that there was no difference in the predation ability between the two phenotypes of the $H$. retardatus larvae. Rather, we hypothesized that, because the arenas were small, the inducing agents, the $H$. retardatus larvae, regardless of their phenotype, were able to gorge themselves on $R$. pirica tadpoles (in fact, we observed that the abdomens of both larval phenotypes were fully distended with swallowed $R$. pirica larvae at the time of 
water exchange and feeding during the experimental period).

Reciprocal phenotypic plasticity may be a primary determinant of morphology in $R$. pirica tadpoles in natural pond habitats and a key ecological factor in the community assemblage. In predator-prey interactions, predation success depends greatly on the balance between the gape size of $H$. retardatus larvae and the body size of $R$. pirica tadpoles (i.e., the broader the head that an $H$. retardatus larva has, the larger the range of body size of $R$. pirica tadpoles that it can swallow) (Ohdachi 1994, Kishida and Nishimura 2004). The increased expression of the bulgy phenotype in $R$. pirica tadpoles would be adaptive when they are exposed to predation risk from the more dangerous predator, the predaceous $H$. retardatus larvae.

The modified phenotypic design would alter the predator-prey interaction and affect the fitness not only of the $R$. pirica tadpoles themselves but potentially also that of their predator, the $H$. retardatus larvae. The altered predator-prey interaction resulting from the reciprocal phenotypic plasticity of the $R$. pirica tadpoles might affect ecological processes in the natural community assemblage at various levels via direct or indirect effects on other members of the assemblage. Identification of reciprocal phenotypic plasticity in natural systems and examination of its influences on the ecological patterns in community assemblages are needed to understand the ecological consequences of phenotypic plasticity (Miner et al. 2005).

What signals did the $R$. pirica tadpoles utilize to recognize the phenotype of the inducing agent during the induction process, resulting in the differences in the degree of the bulgy response between the treatments in the experiment? The tadpoles subjected to the two treatments in each aquarium shared the same water, suggesting that the $R$. pirica tadpoles recognized the phenotype of the inducing agent by means of qualitatively or quantitatively different nondiffusible signals during close interaction, perhaps even by direct contact. The number of tadpoles preyed upon did not differ between the treatments throughout the experiment, indicating that the difference in the extent of the bulgy response did not reflect the number of preyed-upon tadpoles.

The proximate signal recognition of the inducible defense leads us to hypothesize that the result may reflect more frequent direct contact via predaceous attack by the inducing agent (i.e., the tadpoles exposed to the predaceous $H$. retardatus larvae experienced more persistent attacks than those exposed to the typical $H$. retardatus larvae, resulting in a difference in signal perception). However, this hypothesis is likely excluded by the fact that the number of the tadpoles preyed upon between the treatments did not differ. The inducing agents in both treatments reached satiety during the experiment, suggesting that tadpoles with typical larvae would have experienced more frequent attacks than those with predaceous larvae, since the predation success of the typical larvae would be lower than that of the predaceous larvae.

It is more likely that the $R$. pirica tadpoles utilized phenotype-specific signals to distinguish between the predator phenotypes. During the preliminary induction of the predator phenotype, before the experiment, the $H$. retardatus larvae destined to have the predaceous phenotype were fed $R$. pirica tadpoles to induce the predaceous phenotype, whereas those larvae intended to have the typical phenotype were fed chironomid larvae so that they would retain that morph. Of course, in natural systems, $H$. retardatus larvae with the predaceous phenotype would have preyed on $R$. pirica tadpoles during their development, because a high density of $R$. pirica tadpoles is required to induce the predaceous phenotype (i.e., a past history of predation on $R$. pirica tadpoles is intimately related to the predaceous phenotype). In general, prey organisms, including anuran tadpoles, are sensitive to originating from injured or preyed-upon conspecifics (i.e., alarm substances; e.g., Schoeppner and Relyea 2005). R. pirica tadpoles may adjust their development of the bulgy morph according to the phenotype of $H$. retardatus larvae to which they are exposed by utilizing memories of alarm substances which have been stored in the nondiffusible signals.

The reciprocal plastic response of the bulgy phenotype of $R$. pirica tadpoles may have evolved in the course of an arms race of the two phenotypic plasticities between the two larval amphibians (i.e., the inducible bulgy phenotype of $R$. pirica tadpoles and the inducible predaceous phenotype of $H$. retardatus larvae). Previous studies have reported some evidence supporting the coevolution of reciprocal phenotypic plasticities. For example, our recent study showed that the signal recognition system for induction of the bulgy phenotype and the morph's adaptive function in $R$. pirica tadpoles are specific to $H$. retardatus larvae (Kishida and Nishimura 2005). In addition, geographical differences in the ability of tadpoles to adaptively express the bulgy phenotype correspond to differences in the geographical distribution of $H$. retardatus (O. Kishida and $\mathrm{K}$. Nishimura, unpublished manuscript). R. pirica tadpoles from the mainland, where the salamanders are common, express the bulgy phenotype more than tadpoles from an island without the predators. Thus, the bulgy plastic phenotype has been selected for by predation pressure from larval $H$. retardatus. Conversely, induction of the predaceous phenotype in $H$. retardatus larvae seems to be specific to $R$. pirica tadpoles. $R$. pirica tadpoles are the only other amphibians with which $H$. retardatus larvae interact. Although $H$. retardatus larvae with the predaceous phenotype occur not only where the density 
of $R$. pirica tadpoles is high but also where the density of conspecific larvae is high, the induction rate is higher in the former environment than in the latter (Michimae and Wakahara 2002). The specificity suggests that this plastic phenotype has evolved during intimate interaction with $R$. pirica tadpoles. $R$. pirica tadpoles might have evolved reciprocal phenotypic plasticity as a survival strategy in their highly antagonistic interaction with $H$. retardatus larvae.

\section{ACKNOWLEDGMENTS}

We thank Akihiko Mougi, Tadashi Iwami, and Gen Miyazaki for time devoted to assisting with the experimental work. We also thank Hirofumi Michimae, Saburou Mougi, Mikio Mizuta, Tamiko Mizuta, Ami Suzuki, Takashi Matsuishi, Toyomi Takahashi, Masanori Yokoyama, and Tsutou Hirose for their advice and support. We are also grateful to anonymous reviewers for very constructive and helpful comments on the manuscript. This work was supported by a Grantin-Aid for Scientific Research (no. 16370008) to K. Nishimura from the Ministry of Education, Culture, Sports, Science, and Technology, and in part by a Grant-in-Aid for a Research Fellow of the Japan Society for the Promotion of Science for young scientists (no. 09035) to O. Kishida.

\section{Literature Cited}

Agrawal, A. A. 2001. Phenotypic plasticity in the interactions and evolution of species. Science 294:321-326.

Aubret, F., R. Shine, and X. Bonnet. 2004. Adaptive developmental plasticity in snakes. Nature 431:261-262.

Benard, M. F. 2004. Predator-induced phenotypic plasticity in organisms with complex life histories. Annual Review of Ecology, Evolution, and Systematics 35:651-673.

DeWitt, T. J., and S. M. Scheiner. 2004. Phenotypic plasticity: functional and conceptual approaches. Oxford University Press, New York, New York, USA.

Frankino, W. A., and D. W. Pfennig. 2001. Conditiondependent expression of trophic polyphenism: effects of individual size and competitive ability. Evolutionary Ecology Research 3:939-951.

Hoffman, E. A., and D. W. Pfennig. 1999. Proximate causes of cannibalistic polyphenism in larval tiger salamanders. Ecology 80:1076-1080.

Kishida, O., and K. Nishimura. 2004. Bulgy tadpoles: inducible defense morph. Oecologia 140:414-421.

Kishida, O., and K. Nishimura. 2005. Multiple inducible defences against multiple predators in the anuran tadpole, Rana pirica. Evolutionary Ecology Research 7:619-631.

Kopp, M., and R. Tollrian. 2003. Reciprocal phenotypic plasticity in a predator-prey system: inducible offences against inducible defences? Ecology Letters 6:742-748.

Michimae, H., and M. Wakahara. 2001. Factors which affect the occurrence of cannibalism and the broad-headed "cannibal" morph in larvae of the salamander Hynobius retardatus. Behavioral Ecology and Sociobiology 50:339345 .

Michimae, H., and M. Wakahara. 2002. A tadpole-induced polyphenism in the salamander Hynobius retardatus. Evolution 56:2029-2038.

Miner, B. G., S. E. Sultan, S. G. Morgan, D. K. Padilla, and R. A. Relyea. 2005. Ecological consequences of phenotypic plasticity. Trends in Ecology and Evolution 20:685-692.

Ohdachi, S. 1994. Growth, metamorphosis, and gape-limited cannibalism and predation on tadpoles in larvae of salamanders Hynobius retardatus. Zoological Science 11:127-131.

Pigliucci, M. 2001. Phenotypic plasticity: beyond nature and nurture. Johns Hopkins University Press, Baltimore, Maryland, USA.

Relyea, R. A. 2002a. Competitor-induced plasticity in tadpoles: consequences, cues, and connections to predator-induced plasticity. Ecological Monographs 72:523-540.

Relyea, R. A. 2002b. Costs of phenotypic plasticity. American Naturalist 159:272-282.

Schlichting, C. D., and M. Pigliucci. 1998. Phenotypic evolution: a reaction norm perspective. Sinauer, Sunderland, Massachusetts, USA.

Schoeppner, N. M., and R. A. Relyea. 2005. Damage, digestion, and defence: the roles of alarm cues and kairomones for inducing prey defences. Ecology Letters 8:505-512.

Smith, L. D., and A. R. Palmer. 1994. Effects of manipulated diet on size and performance of Brachyuran crab claws. Science 264:710-712.

Stearns, S. C. 1989. The evolutionary significance of phenotypic plasticity. BioScience 39:436-445.

Teplitsky, C., S. Plenet, J.-P. Lena, N. Mermet, E. Malet, and P. Joly. 2005. Escape behaviour and ultimate causes of specific induced defences in an anuran tadpole. Journal of Evolutionary Biology 18:180-190.

Tollrian, R., and C. D. Harvell. 1999. The ecology and evolution of inducible defenses. Princeton University Press, Princeton, New Jersey, USA.

Trussell, G. C., P. J. Ewanchuk, and M. D. Bertness. 2002. Field evidence of trait-mediated indirect interactions in a rocky intertidal food web. Ecology Letters 5:241-245.

Van Buskirk, J., and R. A. Relyea. 1998. Selection for phenotypic plasticity in Rana sylvatica tadpoles. Biological Journal of the Linnean Society 65:301-328.

Werner, E. E., and S. D. Peacor. 2003. A review of traitmediated indirect interactions in ecological communities. Ecology 84:1083-1100.

Wicklow, B. J. 1988. Developmental polymorphism induced by intraspecific predation in the ciliated protozoan Onychodromus quadricornutus. Journal of Protozoology 35:137-141.

Wilson, R. S., P. G. Kraft, and R. Van Damme. 2005. Predator-specific changes in the morphology and swimming performance of larval Rana lessonae. Functional Ecology 19: $238-244$. 